to" acts, but the repetition of any activity at all which reminds the patient of the past structure of her life. The steadiness of this structure has been greatly disturbed by the experience of depression. Putting out milk bottles, locking the front door, feeding the cat, may all acquire a new significance in that they can give the patient a hint of achievement, a sense of not succumbing completely to negative forces.

Help: The patient longs for outside help and yet, after a while, realises that no-one can work miracles and take depression away. It has to be lived with, and the undepressed times duly treasured. When depression lifts, there may be a sudden access of energy and activity; it is important to remember that overtiredness is then a danger. Trying to make up for lost time, too quickly, may lead back to depression. The patient may find that she still needs reassurance and this may be puzzling to the outside world. She needs to feel that she is doing all right at work or at home when it is obvious to others that all is well. The question remains "Am I now me?" and the doubt "How long will this last?" Much work on depression has raised the status of this debilitating illness; it has also brought a variety of remedies that can be tried. But, caught in a cycle depression, the patient repeats again and again the same question to the medical profession:

Canst thou not minister to a mind diseas'd, Pluck from the memory a rooted sorrow,

Raze out the written troubles of the brain ... ? (Macbeth, V.iii. 40-42)

There is no "sweet oblivious antidote", but the patient, in the 1980's, will, at least, be offered help.

Lecturer in English, Mrs Ruth Pitman

University of Bristol,

3-5 Woodland Road,

Bristol BS8 1TB

\section{THYROID ABNORMALITIES AND VIOLENT SUICIDE}

DEAR Sir,

We note with interest the study of 51 women by Linkowski and colleagues, (Journal, October 1983, 143, 401-405). A poor TSH response to TRH was associated with a history of violent suicide. Three of the patients with an abnormal TSH response subsequently died by violent suicide. This prompted us to examine our own data of patients who attended the Maudsley Hospital and subsequently died by suicide as determined by the coroner's court. Forty eight case records were randomly selected from the Camberwell Register.

Four of our sample, all females, had abnormalities

of thyroid function diagnosed and subsequently died by violent suicide:

Case 1. This patient suffered from depression and erotomania. At the age of 50 she was noted to have a repeatedly raised $\mathrm{PBI}$ and $\mathrm{T} 4$. Two years later she died by cutting her throat. She had previously made suicidal attempts by throwing herself under a train, running out into the road in front of traffic and had taken several overdoses.

Case 2. Thyrotoxicosis was diagnosed at the age of 29 and treated by partial thyroidectomy. Eleven years later she was diagnosed as suffering from paranoid schizophrenia. At this time her thyroid function tests were abnormal. She drowned herself 2 months later whilst being assessed for treatment of her thyrotoxicosis.

Case 3. Thyrotoxicosis was diagnosed and treated by partial thyroidectomy at the age of 34 . She subsequently presented to the hospital and was diagnosed a paranoid personality with depression. At the age of $\mathbf{4 0}$ she threw herself out of a window to her death.

Case 4. At 66 myxoedema was diagnosed and treated with thyroxine. Subsequently she was noted to be clinically and chemically hyperthyroid and at other times hypothyroid due to poor compliance. Agitated psychotic depression was subsequently diagnosed at a time when she threw herself under a train and narrowly escaped death. She killed herself by hanging aged 69 .

Whilst our data are not directly comparable with those of Linkowski et al. they must add weight to the hypothesis that violent suicide is associated with abnormalities of the hypothalamopituitary thyroid axis.

\section{St Mary's Hospital, Praed Street, London W2}

The Maudsley Hospital, Denmark Hill, London SE5

Charing Cross Hospital, Fulham Palace Rd, London W6

\section{MIANSERIN AND WARFARIN}

DEAR SiR,

With reference to the recent correspondence of Dr Warwick and Professor Mindham (Journal, September $1983,143,308$ ) concerning a case of drug interaction between mianserin and warfarin, we should like to point out that there are suitable warnings 